\title{
INDICATORS OF THE GLOBAL REPORTING INITIATIVE REGARDING SUSTAINABLE DEVELOPMENT
}

\author{
Leontina Bețianu ${ }^{l}$
}

\begin{abstract}
Ample debates took place and numerous methods were elaborated in order to assess the environment performance of an entity. The simplest and fastest method consists in applying environment indicators which can present the multitude of environment data in a much clearer format. Environment indicators play an important role in decision making and this is why numerous organisms and institutions are interested in their development. This article presents the activities of GRI with regard to this issue.
\end{abstract}

Key words: environmental indicators, annual report, sustainable development

Jell Codes: $M 1, M 4, Q 5$

\section{What is GRI?}

The Global Reporting Initiative (GRI) [GRI, 2002] is an international institution the duty of which is to establish guiding lines for the publishing of nonfinancial information regarding sustainable development. It was set up further to an initiative of the non-governmental organizations (NGOs) and of the big companies of Boston by CERES in partnership with UNEP. Initiated in 1997, GRI became independent in 2002. GRI benefits from the active participation of the representatives of the business, accounting, investments, human rights, environments research, labour sector, etc. all over the world and aims at ensuring the quality of reports having in view to cater for the comparability, reliability and assessment of the submitted information. The adoption of GRI is the result of a voluntary approach, in the absence of any provision binding its application [Quairel, 2004]. According to the study of KPMG 2008, more than three-quarters of the G250 and nearly 70 percent of the N100 use the GRI Guidelines for their reporting [KPMG, 2008].

GRI stands for sustainable reporting in terms of economic, environment and social performances (approach known as the triple bottom line) [GRI, 2006]. The term alludes to the last line of balance sheet and also refers to the three " $p$ " (people, planet, profit), being assimilated to the report "population, planet, profit" published by Shell company in 2005, when it presents the actions carried out in favour of sustainable development, and the objectives established for the future period. At present, this report has become synonymous with the triple bottom line reporting. This approach is based on the idea that the overall performance of an entity can be measured depending on the contribution to economic prosperity, to the quality of the environment and of the share capital. In a narrow sense, this notion refers to the framework permitting the measurement and reporting of the results of an entity according to economic, social and environment parameters. In a wider sense, the term refers to the totality of processes that an entity carries out to minimize the effects of its activity and create new economic, social and ecologic values. This implies a clear purpose of the entity and the consideration of all the users' needs (shareholders, clients, employees, trade partners, public authority, etc.) [Pulselli all, 2006].

This triple approach of sustainability is a reliable means of dealing with complex issues. In fact, GRI continuously analyses and improves the content of the information of reports according to an optimum means of measurement of the sustainable development reports published by entities,

1 „Al.I.Cuza” University of Iasi, FEBA, Department of Business Administration, Carol I Blvd., No.22, 700505, Iasi, betianu@uaic.ro 
specifying that the boundaries of a sustainable development report may affect all the entities which have a considerable (real or potential) impact on the environment and/or over which the entity exercises a significant control or influence in matters of financial and operational policies and practices [GRI, 2006].

In this paper considered the presentation and analysis of eco-efficiency indicators developed by some international institutions. In this literature was examined and the rules and reglementation on environmental indicators, and then were analyzed annual reports and sustainable development published by various companies. In the literature were considered primarily [Depoers, 2004], [Fiorillo et al., 2007], [Hardi et al., 2000], [Labouze, 1993], [GRI 2006, 2002], [Mikol, 2004], [Moneva et al., 2006], [Pulselli et al., 2006], [SAM Group et al., 2006], [Schoer, 2007], [Siracusa et al., 2004], [World Bank, 2001, 1997]

\section{GRI vis-a-vis financial report}

GRI is influenced by the accounting standards of IASB and FASB presenting the objectives, the description of the reporting perimeter, the permanent character of the methods, the comparability and quality of the published information to be taken into consideration when elaborating a report. In 2006, the previous framework, published in 2002) was brought up to date, bearing the name of G3. The latter ameliorates the previous provisions for an easier use and for the establishment of a series of more pertinent, comparable and assessable indicators.

From a technical viewpoint, it seems a management reference system rather than an accounting framework of standardization. GRI does not regulate the conduct of an entity but, rather helps in describing the result of the adoption and application of some management practices, policies and systems. GRI's approach to standardize the content of a report is minimal. The configuration of the report is left to the scope of the entity and to the eventual pressure of the users, the mimesis and the market being the sole constraints for the voluntary publishing approach.

Throughout time, informing rules were elaborated for financial reporting with a view to increase the degree of transparency of the reporting process. GRI strives to orient economic, environment and social performances of reporting in a similar direction, by creating a generally accepted framework of the economic, environment and social performances, that:

- presents the principles of reporting and the specific content orienting the drafting of sustainable development reports at the level of an entity;

- helps the entities present a balanced and objective image of their economic, environment and social performance;

- promotes the comparability of sustainable development reports, by taking into account the practical considerations related to the supply of information by a series of various entities, many of them carrying out activities on a wide geographic area.

- supports the elaboration of standards and assessment of sustainable development, in relationship with the standards of performance and voluntary initiatives;

- serves as an instrument to facilitate the gearing of the interested partners.

GRI reports must provide the necessary information for the concerned parties. The group of sustainable development reports users exceeds that of financial reports users and, thus it is vital to guarantee that the process and content of the reporting reflect the needs of a wide variety of users. Each category of users needs some information that coincides with those of other groups, or sometimes differs. Failure to identify and consult the concerned partners may result in the elaboration of less relevant reports for the users' needs. As a result, such reports are less reliable, as well. On the contrary, the systematic gearing of the concerned parties increases the degree of receptivity and usefulness amongst the various categories of users.

The persons familiar with financial reports shall be capable of identifying overlapping between the principles of GRI reporting and those of financial reporting. Although the financial 
reporting is a starting point in elaborating the principles of reporting of economic, environment and social performances, there exist substantial differences between the two types of reports.

\section{GRI Principles of Reporting}

The majority of entities publish separate financial and environment reports. However, some companies began experimenting the publishing of a single yearly report that includes financial, economic, environment and social information. GRI believes that both financial and sustainable development reports complete each other. GRI encourages the coordination between the two reporting processes and hopes that, as time passes, financial performance assessment shall be beneficially influenced by the assessment of economic, environment and social performances.

The reports must contribute to the approach of the performance of the entity within the broader background of the challenges, risks and opportunities implied by sustainable development. The information of the report must meet the integrity requirement in relationship with the limits of reporting (for instance the included entities), with the sphere of inclusion (that is the aspects or issues dealt with) and with the time framework of the reporting. The reported information must be relevant to fulfill the concerned partners' needs of decision - taking.

The three variants published by GRI $(2000,2002,2006)$ suffered significantly important amendments through the modification of the ancient principles and the emergence of new ones. In this respect, G3 identifies [GRI, 2006]:

- principles of defining the content of the report: relevance, inclusivity (all-inclusive character), sustainable development context, complete character;

- principles of defining the quality of the report: neutrality, clarity, precision, convenient character.

Relevance is the degree of importance attributed to an aspect, indicator or specific information and it stands for the threshold from which the information become significantly enough to be reported. The relevance of sustainable reporting is determined by the significance of a piece of information for the users' decision - taking process. The significance of information may be assessed from various viewpoints; however, the most important perspective is that of the user of information. The essential purpose of reporting (unlike other categories of relations and means of communication) is that coming as a response to the user's need of information, in a neuter and balanced manner. Due to this fact, the process of reporting stresses upon the users' specific needs.

The principle of the all-inclusive character has its roots in the premises that the concerned partners' viewpoints are indispensable to the elaboration of some adequate reports and should be taken into consideration throughout the process of project drafting [Jianu, 2007]. The entities must involve both the directly and indirectly concerned partners. The aspects of reporting that may be enriched by consulting the concerned partners include (but not limit themselves to) the choice of indicators, to the definition of the limits of reporting for the respective entity, to the format of the report, as well as to the approaches adopted for ensuring information reliability.

Context of sustainable development. Entities should try to present their performance in the broader context of the limits or constraints of ecological, social or other sort of nature. Many aspects of sustainability reporting acquire more importance in the broader context of the way in which the performance of the entity affects the formation and deterioration of economic, environment and social capital at a local, regional or world level. In such cases, the mere reporting of the tendency of individual performance (or of entity efficiency) does not reveal its contribution to the quantum of the various types of capital. For certain users, the presentation of the performance related information in the broader bio-physical, social and economic context constitutes the main element of sustainability reporting and represents one of the major factors of differentiation between these types of reporting and financial reporting [GRI, 2006].

Comprehensiveness. All the pieces of information that are essential to the users for the evaluation of the economic, environment and social performance of an entity must be presented in 
the report in such a manner as to reflect the declared limits, space dimensions and time period. This principle refers to the taking of responsibility for the sufficiently detailed presentation of all the pieces of information that are significant to the interested partners, within the declared limits (operational, space and time related) of the report. The establishing of the extent to which this information is significant to the interested partners will be achieved via their consultation.

Neutrality. The essential objective of the selection and communication of information by an entity is to present an objective description of its performance. This involves a presentation which includes both positive and negative outcomes, an impartial presentation, without the tendency to under or overestimates the performances of the entity, the avoidance of selections, omissions or of presentation modalities meant to influence the user's decision.

The principle of clarity refers to the extent to which the information can be understood and used by various groups of users. In financial reporting, there is an unwritten rule related to the general level of knowledge and experience of the group of "primary" potential users, namely the investors. The users of environment reports are diverse and one can assume that they have certain knowledge concerning at least some of the economic, environment and social issues faced by the entity who publishes the information. However, not all groups have the same level of experience and this is why entities should elaborate reports that meet the needs of a large number of users, without sacrificing the details that are of interest only to a subgroup of users. Technical and scientific terms should be explained in the report, with the help of clear and adequate charts, whenever necessary. Providing information that cannot be understood by the users will not contribute to successfully attracting them.

The accuracy of the information is determined to a great extent by the degree of clarity, detail and balance of the presentation. Economic, environment and social indicators can be expressed in various modalities, providing more or less detailed qualitative and quantitative information. On the other hand, the accuracy of quantitative information depends on the specific methods of selection of the samples used for data collection. The specific and necessary precision threshold will depends, to some extent, on the way the information is to be used. Certain decisions will require a greater degree of precision of the reported information than others.

The opportune nature involves providing information at the right moment, so that it can be used in decision making. Just like in financial reporting, the reporting related to economic, environment and social performance becomes more useful when the users rely on a predictable schedule for the providing of the information. Special updates can be made when unexpected evolutions, of particular interest to the users, occur.

The principles of accuracy and opportune nature refer to the access modality and to the availability of the reports. In other words, interested users should receive information that is easy to understand and in due time, so that they are able to efficiently use it. Entities should become informed about the needs and conditions of the various groups of interested partners, striving to render the information available for a maximum number of users, preserving, at the same time, an adequate level of detail.

Comparability is closely related to the objective of building a reporting frame to complete the frame of financial reporting. The conditions of conformity reporting contribute to the promotion of the GRI commitment to obtain a maximum degree of comparability between reports via the creation of a common reference point for those who choose this option.

The reliability of the content of the report is guaranteed by the accuracy, neutrality and comparability of the presented information. The information must be sufficiently accurate so that they can be used in decision making. It is also important for the reports to present the content in a balanced and objective manner, and the presented information must be comparable in time and between entities. Interested partners wish to be able to trust the environment report of an entity, and companies wish to take measures in order to increase the credibility of their reports. 
The verification of the published data is essential for guaranteeing the credibility of the reports. The reported data and information should be collected, recorded, analyzed and presented in such a way as to enable internal and external auditors to confirm their credibility.

These principles established by GRI contribute to making sure that the reports:

- present a balanced and objective rendering of economic, environment and social performances and, consequently, of the contribution of the entity to sustainable development;

- facilitate comparisons in time;

- facilitate comparisons between companies; and

- credibly approach the issues that concern the interested partners.

All the information that is essential to the users for the evaluation of economic, environment and social performance must be presented in the report in such a manner as to reflect the declared limits, space dimensions and time period.

\section{GRI indicators}

Apart the contribution it has to the execution of internal financial analysis, the information on environment performances also plays an important role in traditional financial reports [Depoers, 2004]. Some top companies have already started to experiment by compiling the environment and financial reports as a single annual report. Even the presentation in separate documents is of significant value in cross analysis. Some categories of standard data and information in financial reports can and must include aspects of the performance of sustainable development. For example, the reduction of the flows of waste, which determines smaller costs, should appear under the form of smaller expenses in the financial report, and the money resulted from the recycling of waste should be mentioned as income.

Despite the increasingly numerous overlaps between sustainable development and financial reports, the greatest difficulty of joining financial and sustainable development reporting consists in the transformation of economic, environment and social indicators into financial indicators.

Many indicators of sustainable development are qualitative and cannot be easily expressed in financial data. The results of the strategies of sustainable development and of the related capital distributions are so uncertain that it is difficult to predict benefits. Usually, financial analysts are interested in the information that is:

- real for the company (represents a measurable change of its income or proceeds for a business segment);

- expressed in financial terms;

- provisional (provides data concerning the tendencies of entity performance).

When reporting environment indicators, entities are encouraged to take into account the principle of the context of sustainable development and to relate their individual performances to the broader ecological systems in which they operate. For example, entities could relate the generated emissions to the capacity of the (local, regional or global) environment to absorb them.

GRI developed a set of performance measures-keys applicable to all entities, sets of measures specific to certain types of companies and a uniform format for the reporting of the information concerning the economic, environment and social performances of an entity. GRI structures performance indicators according to a specific hierarchy, depending on category, aspect and indicator. The indicators are grouped depending on the three dimensions from the conventional definition of sustainable development - the economic, environment and social dimension.

These indicators provide information on the performed actions and the anticipation of some risks [Emtairah, 2002]:

- the knowledge of the use modality of direct and indirect energy and of the type of fuels consumed by the entity can show its degree of exposure to the risks of future agreements and regulations concerning the emissions of $\mathrm{CO}_{2}$; 
- the performance indicators concerning the efficient use of energy and the use of renewable energy can contribute to the demonstration of the degree of independence of the entity in relation to the unstable and cyclic markets of non-renewable energy;

- the indicators concerning the volume, tendencies and nature of the emissions enable the evaluation of the risks to which the entities are subjected as a result of the new environment regulations.

An important argument for relating the performance indicators of sustainable development to traditional financial reporting is the necessity of providing data with the names and terms that are known from the financial reports [Schoer, 2007]. The information concerning sustainable development should be presented for the same units of analysis (business entities, segments and geographical coverage) as those in the financial reports. The information can become even more useful when placed in the context of some standards specific to a particular sector. For example, for the elaboration of the environment and social report, Total, the French group, took into account two international reporting standards: the reporting guide for indicators specific to the oil and gas industry and GRI for extra-financial reporting.

GRI established 79 indicators, 9 for economic performance, 30 for environment performance and 40 for social performance (divided into four groups: 14 for work practices, 9 for human rights, 8 for the company, 9 for product warranty) [GRI, 2006].

According to the KPMG report most companies use the GRI reporting user information environment (fig. no. 1), and G3 indicate the degree of enforcement of rules and indicators (level C - the company must only report 10 GRI indicators, level B - 20 and level A all 50 GRI indicators, and the company can indicate utilized third party assurance by adding a "+" to declared level) (fig. no. 2).

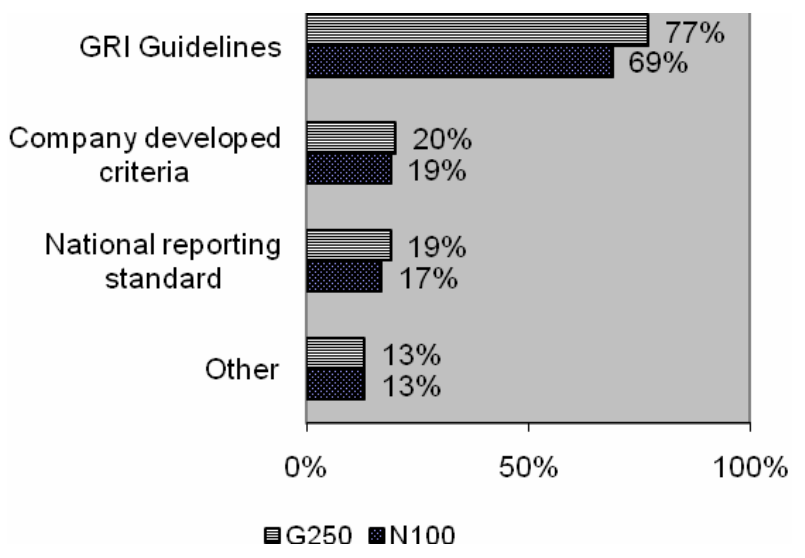

Fig. no. 1 Reporting standards and guidelines used by companies (N100, G250)

Source: KPMG, 2008, International Survey of Corporate Responsibility Reporting, http://www.kpmg.com/ lobal/en/IssuesAndInsights/ArticlesPublications/Documents/Internationalcorporate-responsibility-survey-2008.pdf, .35 


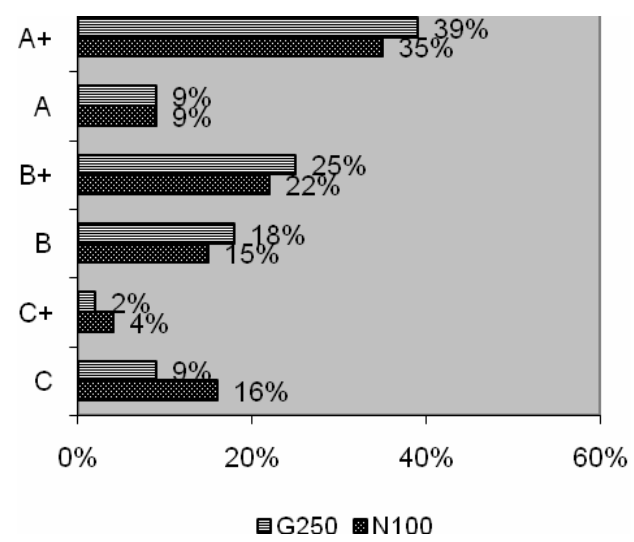

Fig. no. 2 GRI Application Level declarations (N100, G250)

Source: KPMG, 2008, International Survey of Corporate Responsibility Reporting, http://www.kpmg.com/ lobal/en/IssuesAndInsights/ArticlesPublications/Documents/Internationalcorporate-responsibility-survey-2008.pdf, .37

Table no. 1 presents the GRI environment indicators for the French group EDF. In order to present comparable information the group reused the information for the previous years, for in the previous version of GRI there were 35 environment indicators, grouped into primary and secondary indicators (16 primary and 19 secondary).

Indicators GRI by EDF group 2007-2009

\begin{tabular}{|c|c|c|c|c|c|}
\hline Performance indicators & Unit & 2009 & 2008 & 2007 & $\begin{array}{l}\text { GRI } \\
\text { Ref. }\end{array}$ \\
\hline \multicolumn{6}{|l|}{ FINANCE } \\
\hline Provisions for decommissioning and last core & $€$ millions & 20,352 & 14,142 & 13,654 & \\
\hline Provisions for nuclear fuel end-cycle & $€$ millions & $\mathbf{1 8 , 5 7 3}$ & 15,538 & 17,455 & \\
\hline $\begin{array}{l}\text { Compensation paid or to be paid following legal decisions } \\
\text { on environmental matters }\end{array}$ & $\begin{array}{c}€ \\
\text { thousands }\end{array}$ & $\mathbf{8 1 0}$ & NA & 84.5 & \\
\hline \multicolumn{6}{|l|}{ ENVIRONMENT } \\
\hline \multicolumn{6}{|l|}{ Consumables and raw materials } \\
\hline Nuclear reactor fuel & $\mathrm{t}$ & 1,141 & 1,282 & 1,151 & EN 1 \\
\hline Coal & $\mathrm{kt}$ & 24,261 & 25,300 & $5,970,970$ & EN 1 \\
\hline Heavy fuel oil & $\mathrm{kt}$ & 1,798 & 1,950 & $1,457,050$ & EN 1 \\
\hline Domestic fuel & $\mathrm{kt}$ & 447 & 306 & 259,659 & EN 1 \\
\hline Non-industrial gas & $10^{6} \mathrm{~m}^{3}$ & 6,563 & 9,259 & 23,718 & EN 1 \\
\hline Industrial gas & $10^{6} \mathrm{~m}^{3}$ & 2,809 & $\mathbf{5 , 7 1 6}$ & $1,292,403$ & EN 1 \\
\hline \multicolumn{6}{|l|}{ Water } \\
\hline Cooling water drawn & $10^{9} \mathrm{~m}^{3}$ & 52.2 & 45.9 & 41.2 & EN 8 \\
\hline Cooling water returned & $10^{9} \mathrm{~m}^{3}$ & 51.6 & 45.7 & 40.7 & EN 21 \\
\hline \multicolumn{6}{|l|}{ Air } \\
\hline $\begin{array}{l}\text { Total } \mathrm{CO}_{2} \text { emissions (including facilities not subject to } \\
\text { quotas) }\end{array}$ & Mt & 80.2 & 91.6 & 78.3 & EN 16 \\
\hline $\mathrm{SO}_{2}$ emissions & $\mathrm{kt}$ & 203.5 & 192.4 & 209.7 & EN 20 \\
\hline $\mathrm{NO}_{\mathrm{x}}$ emissions & $\mathrm{kt}$ & 160.4 & 168.2 & 194.5 & EN 20 \\
\hline Dust & $\mathrm{t}$ & 8,506 & 7,644 & 5,071 & EN 20 \\
\hline Methane emissions & kt eq. $\mathrm{CO}_{2}$ & 35.8 & 5.3 & 4.8 & EN 16 \\
\hline $\mathrm{N}_{2} \mathrm{O}$ emissions & kt eq. $\mathrm{CO}_{2}$ & 310.8 & $\mathrm{NC}$ & NCEN & EN 16 \\
\hline Hazardous waste & $\mathrm{t}$ & 37,695 & 20,090 & 18,08 & EN 22 \\
\hline Non-hazardous waste & $\mathrm{t}$ & 150,212 & 114,899 & 124,621 & EN 22 \\
\hline
\end{tabular}




\begin{tabular}{|c|c|c|c|c|c|}
\hline Performance indicators & Unit & 2009 & 2008 & 2007 & $\begin{array}{l}\text { GRI } \\
\text { Ref. }\end{array}$ \\
\hline $\begin{array}{l}\text { Conventional industrial waste recycled or transported for } \\
\text { recycling }\end{array}$ & $\mathrm{t}$ & 131,465 & 98,399 & 112,203 & EN 22 \\
\hline Ash produced & $\mathrm{kt}$ & $3,761.5$ & 581,694 & $\mathrm{NC}$ & EN 22 \\
\hline \multicolumn{6}{|l|}{ Energy } \\
\hline $\begin{array}{l}\text { Renewable energy: electricity and heat generated from } \\
\text { renewable sources (excluding hydro) }\end{array}$ & GWh & 8,600 & 6,186 & 4,356 & EN 6 \\
\hline Internal consumption, pumping electricity & TWh & 6.8 & 6.5 & 7.7 & EN 3 \\
\hline Internal consumption, electricity & TWh & 22.4 & 23.3 & 23.1 & EN 3 \\
\hline \multicolumn{6}{|l|}{ Management } \\
\hline Expenditure on environmental protection & $€$ million & 2,477 & 2,496 & 2,733 & EN 30 \\
\hline of which provisions & $€$ million & 1,691 & 1,775 & 1,478 & EN 30 \\
\hline Environmental management (ISO 14001) & \multicolumn{4}{|c|}{$\begin{array}{c}\text { Group-wide Environmental Management } \\
\text { System (ISO 14001) }\end{array}$} & \\
\hline \multicolumn{6}{|l|}{ SOCIAL } \\
\hline \multicolumn{6}{|l|}{ Staff breakdown } \\
\hline EDF SA + ERDF + RTE & no. & 105,129 & 104,929 & 105,322 & LA 1 \\
\hline TOTAL EDF Group & no. & 169,139 & 160,913 & 158,640 & LA 1 \\
\hline Total executives & no. & 36,469 & 33,543 & 31,770 & LA 1 \\
\hline Women at managerial level & $\%$ & 22.0 & 21.2 & 20.5 & LA 13 \\
\hline Staff who are not executives & no. & 132,670 & 127,370 & 126,870 & LA 13 \\
\hline - Male staff & no. & 129,288 & 122,762 & 121,730 & LA 13 \\
\hline - Female staff & no. & 39,851 & 38,151 & 36,910 & LA 13 \\
\hline - Male executives & no. & 28,444 & 26,436 & 25,254 & LA 13 \\
\hline - Female executives & no. & $\mathbf{8 , 0 2 5}$ & 7,108 & 6,516 & LA 13 \\
\hline \multicolumn{6}{|l|}{ Hires/Departures } \\
\hline Recruitment & no. & 12,362 & 12,533 & 11,294 & LA 2 \\
\hline Other hires & no. & $\mathbf{1 0 , 2 3 2}$ & 2,092 & 2,682 & LA 2 \\
\hline Retirement/inactivity & no. & 4,389 & 4,578 & 4,320 & LA 2 \\
\hline Resignation & no. & 2,529 & 3,760 & 3,486 & LA 2 \\
\hline Redundancies, dismissals, termination of post & no. & 1,512 & 1,901 & 1,642 & LA 2 \\
\hline Other departures & no. & 5,983 & 3,083 & 4,572 & LA 2 \\
\hline \multicolumn{6}{|l|}{ Working hours } \\
\hline Part-time staff & no. & 20,145 & 21,971 & 23,964 & LA 1 \\
\hline \multicolumn{6}{|l|}{ Health and safety } \\
\hline Fatal injuries & no. & 12 & 13 & 15 & LA 7 \\
\hline Injury frequency rate & & 4.9 & 6.2 & 6.3 & LA 7 \\
\hline Work-related injuries (with 24 hours leave or more) & no. & 1,268 & 1,504 & 1,495 & LA 7 \\
\hline \multicolumn{6}{|l|}{ Management/employee relations } \\
\hline Staff covered by collective bargaining agreements 4 & $\%$ & 94 & 95 & 95 & LA 4 \\
\hline \multicolumn{6}{|l|}{ Training } \\
\hline Staff benefiting from training & no. & 104,565 & 102,629 & 104,393 & LA 10 \\
\hline \multicolumn{6}{|l|}{ Employment and insertion of employees with disabilities } \\
\hline Staff with disabilities & no. & $\mathbf{3 , 3 4 3}$ & 3,364 & 3,260 & LA 13 \\
\hline
\end{tabular}

Source: EDF group, Activity and Sustainable Development Report 2009, pp. 98-100, www.edf.com

The presentation of this information is of utmost importance, and the tendency is that of trying to draw up a single report. Actually, some top companies have already started to try to combine environment and financial reports into a single annual report.

Annual reports must contribute to the approaching of entity performance in the broader context of the challenges, risks and opportunities of sustainable development. The presented information must observe the requirement of integrality in relation to the limits (for example, the included entities), the scope (the approached aspects or issues) and the time frame of the reporting. The reported information must be of relevance for meeting the needs of decision making by the interested partners. 


\section{Conclusion}

An important argument for relating the performance indicators of sustainable development to traditional financial reporting is the necessity of providing data with the names and terms that are known from the financial reports. The information concerning sustainable development should be presented for the same units of analysis (business entities, segments and geographical coverage) as those in the financial reports. The information can become even more useful when placed in the context of some standards specific to a particular sector.

The performance indicators used in sustainable development reports seldom fulfill the criteria applied in financial reporting. These require additional processing or contextual approaches so that they can be used directly in financial analyses. Hence, new methodologies for relating economic, environment and social performance with financial performance are needed. As in the case of other instruments for business analysis, the fundamental premises and measurements must be individualized according to industrial sectors in order to ensure significant and comparable performance standards.

\section{References}

1. Depoers, F, 2004. Comparabilité des indicateurs environnementaux: l'exemple des gaz à effet de serre, Revue Française de Comptabilité, n 365, avril, p.17

2. Depoers, F., 2004. Reporting environnemental: une comparaison GRI/NRE, Revue Française de Comptabilité, $n^{\circ}$ 364, mars, pp. 17-18

3. Emtairah, T., 2002. Corporate Environmental Reporting. Review of Policy Action in Europe, Lund, February, http://www.enviroreporting.com

4. Fiorillo, F., Palestrini, A., Polidori, P., Socci, C., 2007. Modeling water policies with sustainability constraints: A dynamic accounting analysis, Ecological Economics, vol. 63, issue 2-3, pp. 392-402

5. GRI, 2006. Ligne directrices pour les rapports de développement durable

6. GRI, 2006. Sustainability Reporting Guidelines, Version 3.0

7. Hardi, P., Muyatwa, P., 2000. Examen de cadres choisis pour les indicateurs de développement durable fondés sur le capital, l'Institut International du Développement Durable, http://www.nrtee-trnee.ca

8. KPMG, 2008. International Survey of Corporate Responsibility Reporting, http://www.kpmg.com/Global/en/IssuesAndInsights/ArticlesPublications/Documents/Intern ational-corporate-responsibility-survey-2008.pdf

9. Labouze, E., 1995. Les indicateurs de la performance environnementale, Revue Française de Comptabilité, no.272, novembre, pp. 77-85

10. Mikol, A., 2004. Les indicateurs écologiques selon l'ONU, Revue Française de Comptabilité, $\mathrm{n}^{\circ} 371$, novembre

11. Moneva, J.M., Pablo Archel, P., Correa, C., 2006. GRI and the camouflaging of corporate unsustainability, Accounting Forum, vol. 30, issue 2, pp. 121-137

12. Pulselli, F.M., Ciampalini, F., Tiezzi, E., Zappia, 2006. C., The index of sustainable economic welfare (ISEW) for a local authority: A case study in Italy, Ecological Economics, vol. 60, issue 1, pp. 271-281

13. Quairel, F., 2004. Responsable mai pas comptable: analyse de la normalisation des rapports environnementaux et sociaux, Revue Comptabilité Contrôle Audit, Tome 10, vol. 1, juin

14. SAM Group, PriceWaterhouseCoopers, 2006. The Sustainability Yearbook 2006, Zurich, Switzerland, http://www.pwc.com 
15. Schoer, K., 2007. Sustainable Development Indicators and Environmental-Economic Accounting, Paper presented at 11th Meeting of the London Group on Environmental Accounting Johannesburg, 26-30 March

16. Siracusa, G., La Rosa, A.D., Sterlini, S.E., 2004. A new methodology to calculate the environmental protection index (Ep): A case study applied to a company producing composite materials, Journal of Environmental Management, no. 73, 275-284

17. World Bank, 2001. World Development Indicators, Washington

18. World Bank, 1997. Expanding the Measure of Wealth: Indicators of Sustainable Development, ESD Studies and Monographs No. 17, Washington: The World Bank 